\title{
A importância de E. T. A. Hoffmann na cena romântica francesa
}

Maria Cristina Batalha

Grâces soient rendues à Musoeus, à Tieck et à Hoffmann, dont les heureux caprices, tour à tour mystiques et familiers, pathétiques ou bouffons, simples jusqu'à la trivialité, exaltés jusqu'à l'extravagance, mais remplis partout d'originalité, de sensibilité et de grâce, renouvellent pour les vieux jours de notre décrépitude les fraîches et brillantes illusions de notre berceau.

Charles Nodier, Contes Fantastiques

A literatura fantástica, como uma combinatória própria de elementos presentes no maravilhoso, surge na França, com as obras Le diable amoureux, de Jacques Cazotte (1792), e Le manuscrit trouvé à Saragosse, de Jean Potocki (1805). A nova modalidade literária inscreve-se no contex to de rejeição ao pensamento teológico e à metafísica, heranças medievais que o Século das Luzes tenta banir de seu horizonte, mas que permaneciam vivas no imaginário do público leitor, explorando as incertezas e relativizando o jogo entre acreditar e não-acreditar. No entanto, as duas obras ficam como manifestações isoladas, presas aos cânones narrativos do século XVIII, e não se impõem como modelo para uma nova escola estética. Na Alemanha, esse percurso foi diferente e, com a retomada da fantasia e da liberdade de criação impulsionados pelo movimento romântico, a literatura fantástica encontrou um campo apropriado para se desenvolver, sobretudo com Hoffmann, nome exponencial dessa modalidade literária, e através do qual o fantástico se reintroduz na França, trazendo um fôlego novo ao movimento romântico nesse país.

A revelação de E. T. A. Hoffmann provocou uma fermentação entre os franceses, nos anos de 1828 até mais ou menos 1840. Até 1828, quando surgem as primeiras traduções francesas de contos do autor alemão, as referências a Hoffmann eram 
" (apud Teichmann, Elizabeth. La fortune d'Hoffmann en France. Genève: Droz et Paris: Minard, 1961: 19.)

" (Ampère, J.J. "Werner. De sa vie et de ses écrits", Globe, VI, 2 e 9 de julho, 1828, apud Teichmann, Elizabeth. La fortune d’Hoffmann en France. Op. cit.: 20.)

- (Castex, Pierre-Georges. Horizons romantiques. Paris: José Corti, 1983: 25-32.) praticamente inexpressivas e esparsas, resumindo-se à simples indicação do nome do autor em antologias gerais.

Quando a Bibliothèque Universelle de Genève publica duas traduções de contos de Hoffmann, seu tradutor, em nota explicativa, coloca o autor "alinhado com outros escritores humoristas da literatura alemã”. Em uma segunda tradução do conto "Desvios de um homem de imaginação", o tradutor de Hoffmann desculpa-se por oferecer ao público a amostra de um gênero que pode parecer "bizarro" a muitos leitores, pois, explica ele, "esse gênero fantástico, metade divertido, metade sério, esse jogo da imaginação que não encontra outro objetivo senão o da própria atividade imaginativa, esse vago que deixa o leitor em dúvida se este se encontra no mundo real ou nas esferas do maravilhoso, tudo isto é pouco apreciado na França, onde se exige o positivo, e onde o leitor não tem a vocação de servir de joguete para o autor como ocorre aqui”* .

A primeira revista importante a lançar Hoffmann foi $L e$ Globe, através de um artigo de Jean-Jacques Ampère, datado de 2 de agosto de 1828. Observando a novidade de seus relatos, o crítico deseja buscar filiações e referências com obras e autores conhecidos, que possam servir de parâmetro para a recepção de Hoffmann e fornecer elementos para sua interpretação junto ao público francês. Vejamos como ele apresenta o autor alemão: Suas novelas não se parecem com nada. Eu não conheço nenhuma obra onde o bizarro e o verdadeiro, o tocante e o atemorizante, $o$ monstruoso e o burlesco, choquem-se de modo mais forte, mais vivo e mais inesperado*.

Segundo Pierre Castex, coube a um de seus fiéis amigos, o doutor Koreff, retratado na pele do personagem Vicente de $O s$ irmãos de São Serapião, empenhar-se para construir a reputação póstuma de Hoffmann, entregando ao barão Loève-Veimars alguns textos para serem traduzidos para o francês*.

A reação de Walter Scott, consagrado escritor escocês e referência para o modelo de romance histórico, foi imediata, descredenciando o excesso de fantasia presente na literatura hoffmanneana. Por entre as críticas dirigidas contra ele, as mais virulentas vêm da pena de Scott, que não somente investe contra sua atitude boêmia, seu temperamento hipocondríaco e suas extravagâncias, mas também contra o próprio gênero adotado por Hoffmann. Koreff, em defesa do amigo escritor, em vez de defender os talentos de contista de Hoffmann, insiste no perfil de "autor maldito", de homem sofredor e miserável e de escritor 
mal compreendido, contribuindo assim para a construção do mito, admirado tanto por seus pares, como pelo público francês de modo geral. $\mathrm{O}$ fato é que, de maio a dezembro desse mesmo ano, a imprensa francesa, grande e pequena, levanta sua voz contra as críticas do autor escocês e sai em defesa de Hoffmann, que tem quatro volumes dos Contes fantastiques circulando no mercado, o que deixa supor uma certa familiarização do público francês com o romântico alemão.

O debate que se desencadeia através da imprensa entre os diferentes jornais, revistas e editores que publicam a obra hoffmanneana é significativo: ele anuncia a transição entre duas épocas na história da literatura e fixa definitivamente a estética romântica como um movimento revolucionário, uma luta contra os preconceitos do chamado "bom gosto", assegurando a liberdade e a autonomia completas da arte. Por esta razão, considera Castex a respeito da querela com Scott:

Essa querela, contudo, não nos parece apresentar um simples interesse anedótico. Hoffmann tende a suplantar Scott no exato momento em que o romantismo se define, entre os escritores do Cenáculo, e depois junto aos Jeunes-France, como um movimento revolucionário, que luta contra os preconceitos do bom gosto para assumir a liberdade do gênio*.

Ao cabo da campanha promovida por seu tradutor, estimulado pelo editor interessado em vender as traduções, a difusão das obras de Hoffmann ultrapassa os limites de um acontecimento literário para esboçar a trajetória de um mito construído por seus divulgadores e pelos artistas que nele vão buscar sua inspiração. A crítica, influenciada pela imagem de homem desregrado e de autor "maldito" do contista, nem sempre conseguia captar a novidade de uma obra que traduzira com tanta propriedade aquilo que lhes parecia pouco familiar. Sainte-Beuve, em nota introdutória a "La Maison déserte", publicada no Globe, de 7 de dezembro de 1830, destaca "uma discreta medida de maravilhoso e de real", mas condena "os desvios caprichosos de um fantástico desenfreado e os devaneios incoerentes de um semi-estado de embriaguez". Assim prossegue o crítico no mesmo artigo:

Surge então Hoffmann que, no limiar das coisas visíveis e na fronteira do universo real, encontrou sabe-se lá que canto obscuro, misterioso e até então desapercebido, no qual ele nos ensinou a discernir reflexos particulares das luzes terrenas, sombras estranhas projetadas, engrenagens sutis e todo um reverso imprevisível de perspectivas naturais e destinos humanos aos quais estávamos todos bem acostumados*.
" (Castex, Pierre-Georges. Le conte fantastique en France: de Nodier à Maupassant. Paris: José Corti, 1951: 55.)

" (Saint-Beuve, Oeuvres complètes d'Hoffmann, p. 1166, apud Teichmann Elizabeth. La fortune d'Hoffmann en France. Op. cit.: 62-3.) 
" (Teichmann, Elizabeth. La fortune d'Hoffmann en France. Op. cit.: 68.)
" (Lambert, José. "Hoffmann en France. Histoire d'une naturalisation". Introdução ao tomo 2 dos Contes fantastiques. Paris: Garnier. Flammarion, 1980.)
Em 1831, Alfred de Musset começa sua "Revista fantástica" no jornal Temps. Em um dos artigos que escreve, ele exalta a literatura alemã pela liberdade de ação que esta faculta a seus escritores e, a título de exemplo, cita o caso Hoffmann, referindo-se à sua vida boêmia e a seu aspecto desleixado, contribuindo assim para a construção do "mito Hoffmann”, identificado com o atributo de "artista maldito", do lado oposto ao do "burguês filisteu":

É em meio a essa gente preocupada que Hoffmann, estimulado pelo ponche e com a calça borrada de tinta como a de Napoleão, encontrava três de seus amigos e entabulava uma conversa de uma hora com cada um, sem que nenhum deles se apercebesse que havia esquecido o chapéu no cabaré*

Ao lado disso, o entusiasmo suscitado pela divulgação do autor faz entrar em cena um novo adjetivo - "fantástico" - , que JeanJacques Ampère e Charles Nodier empregam amplamente, inscrevendo Hoffmann no programa literário que vislumbram para o futuro da literatura na França. Embora a palavra tenha um valor lexical e teórico pouco definido e bastante flutuante, ela servirá para designar um certo tipo de conto literário. Desde sua origem, no final do século XVIII, o fantástico tomou emprestado procedimentos pertinentes a outros gêneros e subgêneros para se constituir como uma modalidade narrativa capaz de expressar uma nova visão do homem. Esta visão se esboçara no final do Século das Luzes e permanecia, agravando as contradições (razão $x$ sentimento, verdade $x$ mentira) que estavam em sua raiz, durante todo o século XIX. Entretanto as obras Le diable amoureux e Le manuscrit trouvé à Saragosse, como ainda estavam estreitamente vinculadas aos modelos narrativos do século anterior, não conseguiam impor-se na cena literária do romantismo francês.

Assim, graças, em parte, à biografia romanceada escrita por Loève-Veimars em 1830, associada às ilustrações de Gavarni, que acompanhavam as edições dos Contes, cria-se em torno do escritor uma lenda de extravagância e excentricidade, além de transformar-se a sua obra em referência para o novo gênero. Contudo, segundo as observações de José Lambert, ${ }^{*}$ a imagem de Hoffmann construída para o público francês carrega as marcas da forte tradição desta literatura nacional. Assim, na edição organizada por Loève-Veimars, a seleção - ou exclusão - dos textos, o privilégio atribuído ao fantástico tanto quanto o enfo- 
que biográfico e legendário acionado como chave de interpretação da obra hoffmanneana são testemunhos de um Hoffmann “naturalizado", conforme sugere o autor. Diz Lambert:

A ausência da narrativa emoldurada nas traduções de contos tirados do Serapionsbrüder, a partir de 1830, e as transformações impostas às rupturas da ficção na maioria das traduções têm um valor simbólico: a superposição da arte e da vida na própria técnica da escritura e nas teorias estéticas, aqui está um dos grandes segredos que separam o Hoffmann germânico de seu irmão naturalizado francês*.

As diferenças observadas ficam por conta, segundo Castex, da falta de inclinação do leitor francês para este tipo de literatura. Citando as observações de Heine, que alerta para a dificuldade deste povo em aceitar a "desrazão", apesar das idéias difundidas pelo romantismo, o crítico sublinha a vocação e o gosto francês voltados para a análise lúcida e a fidelidade aos postulados cartesianos. Constata ele:

Em uma ordem paralela de idéias, o contista francês abandonase com mais dificuldade que o contista alemão à poesia do mito: ele está mais interessado no drama do herói, que coloca no centro da narrativa, sobretudo se esse herói é uma projeção de si mesmo. Assim, o relato fantástico assume um valor análogo ao do diário íntimo ou ao de um documento psiquiátrico*.

Como legado à literatura francesa, Hoffmann deixa receitas próprias para despertar o medo nos leitores, uma série de imagens e de personagens, intuições psicológicas, assim como um gênero narrativo perfeitamente acabado. $O$ certo é que ele vem alimentar a obra de grandes escritores e críticos, para os quais o fantástico hoffmanneano representa bem mais do que um simples repertório de modelos, caricaturas e visões. Para Baudelaire, o mito fabricado por Loève-Veimars se transforma em imagem idealizada do Poeta; Nerval combina a partir de diferentes textos (Le magnétiseur, Les élixirs du diable) dados que virão integrar seu projeto de Le magnétiseur, e, posteriormente, o tema do duplo presente em Aurélia nos dá provas evidentes do diálogo entre as duas poéticas.

O que parece consensual é que, a julgar pelos depoimentos da época, Hoffmann vem injetar um fermento novo e estimulante no romantismo francês. Théophile Gautier nos fornece, através de um manuscrito de juventude repertoriado por Elizabeth Teichmann, uma prova inequívoca do papel da obra hoffmanneana para a série literária francesa do século XIX. Diz ele:
" (Lambert, José. "Hoffmann en France. Histoire d'une naturalisation". Introdução ao tomo 2 dos Contes fan. tastiques. Op. cit.: 21.)

" (Castex, Pierre-Georges. Le conte fantastique en France: de Nodier à Mau passant. Op. cit.: 399.) 
- (Gautier apud Teichmann, Elizabeth. La fortune d'Hoffmann en France. Op. cit.: 64.)
- (Milner, Max. Le diable dans la littérature française: de Cazotte à Baudelaire. Tomos 1 e 2. Paris: José Corti, 1960. 1960, tomo 1 : 269.)

' (Castex, Pierre. Horizons romantiques. Op. cit.: 15-8.)
Vemos chegar ao horizonte literário, no qual, desde muito tempo, nós vislumbrávamos apenas frágeis esquifes paramentados com as cores do momento, uma embarcação de porte nobre, navegando a todo vapor, trazendo na proa um desses nomes que despertam a atenção à direita e à esquerda: Hoffmann, o fantastiqueiro (le fantastiqueur), com sua carga de contos inéditos que nada devem aos de seus antecessores*.

Pode-se explicar o interesse pela literatura de Hoffmann por dois motivos fundamentais: primeiro, um certo esgotamento do romance histórico no período do final dos anos 1820 e início dos anos 1830; segundo, uma saturação da tradição do roman noir inglês. Embora a literatura de imaginação e a literatura de observação sigam caminhos diametralmente opostos, a admiração suscitada pelo contista fantástico alemão pode se justificar pelo fato de que ele faz a ponte de ligação entre as duas estratégias narrativas, ou seja, a da fantasia e a da observação minuciosa da vida real. Sua obra ficcional vem então estabelecer um elo entre o roman noir e o romance histórico, ambos já em um ponto de esvaziamento para o público da época.

Conforme assinala Castex, a partir de 1820 define-se uma escola propriamente "frenética", que desenvolve uma nova mitologia para exprimir as angústias e as ambições do homem moderno. Ao feérico, vem opor-se o frenético que chega à França com o "roman noir" inglês e seu cortejo de castelos, ruínas, paisagens lúgubres, fantasmas sanguinários e malfeitores capazes das piores crueldades. Com efeito, após os anos revolucionários, o terror havia se popularizado e ao Terror e seus horrores "reais" vinham se substituir os horrores "imaginários". O termo "frenético" é empregado pela primeira vez por Charles Nodier em 1821, em um artigo dos Annales de la Littérature et des Arts $^{*}$ e surge como um revigoramento do roman noir, devido ao grande sucesso angariado pelas traduções francesas de Maturin e de Byron, que vêm encontrar uma tendência, já manifesta, de uma literatura afeita ao terror e ao sobrenatural.

A verdade é que a exploração das técnicas características dessa literatura de impacto sobre a emoção do leitor orientava de certo modo uma boa parte da produção literária dos primeiros anos da década de 1820. Não mais se contentando em levar às últimas conseqüências o limiar de uma experiência singular, a imaginação literária vai buscar recursos no além e no surreal* . Seres deformados, feiticeiros e vampiros invadem a literatura, 
não apenas a dos autores de folhetins e melodramas menores, mas também as obras de Balzac (Le centenaire e L'elixir de longue vie) e de Victor Hugo (Han d'Islande). Nesta obra de 1823, por exemplo, Hugo exalta a selvageria bestial e o terror de dois personagens - um homem e um urso - dentre os quais o leitor se pergunta qual é o animal mais feroz e sanguinário.

Como vimos, é o roman noir que engendra o frenético e, antes de degenerar-se em obras de gosto pelo menos duvidoso, provocando a reação dos críticos que alertavam para os riscos desse tipo de literatura, alimentou a obra ficcional de grandes autores como Lewis, Maturin e Byron, por exemplo, responsáveis, aliás, pela introdução da literatura frenética na França. À temática e às peripécias do roman noir somaram-se os novos temas de importação alemã, penetrando progressivamente nas esferas superiores da literatura francesa.

No entanto, de um modo geral, dos grandes mestres do gênero, os franceses não retêm senão algumas fórmulas e imagens de efeito, negligenciando, na maioria das vezes, o essencial e o inovador que eles poderiam trazer. Diante da má reputação angariada, a moda do frenético declina à medida que a crítica se apressa em descreditar os excessos desses relatos. A reputação dessa literatura de imaginação frenética se vê então abalada, seja pelos apelos ao bom senso e ao bom gosto, seja pela retomada paródica de certos temas e criações de inspiração frenética. E os próprios escritores, temerosos de verem suas obras confundidas com esses excessos delirantes e os apelos a sentimentalismos baratos endereçados a um público leitor ávido por emoções fortes, vêm em defesa do retorno a um "bom romantismo".

Por outro lado, com os episódios da Revolução de Julho - as Três Gloriosas - a política entra em cena e o debate ideológico ganha a imprensa, contaminando também a crítica literária. No entanto, como uma reação à nova invasão do domínio da literatura pelo prosaísmo e pela realidade social e política, a obra de Hoffmann encontra as condições ideais de sucesso, pois, assim como havia ocorrido no final do Século das Luzes, o fantástico se apresentava como um meio eficaz de escapar à realidade.

$\mathrm{Na}$ verdade, aquilo que Hoffmann apresenta à geração romântica francesa é uma atitude diante da vida, em resposta ao desencanto e à nostalgia, consciente ou inconsciente, dessa geração. Assim, durante o período compreendido entre 1830 e 
1833, a lenda de Hoffmann, com seus ataques e defesas, constrói-se, formando uma série de adeptos fervorosos do escritor alemão. É então na trilha de uma tendência já manifesta no espírito dos escritores da época, e aperfeiçoando as técnicas bem como a temática presentes na literatura "frenética", que a obra de Hoffmann encontra um campo fértil para florescer no cenário literário francês.

A publicação do romance de Balzac La Peau de chagrin, em 1831, suscita comentários e aproximações com a obra de Hoffmann, como podemos ler nos jornais e revistas críticas da época. Neste romance, que Balzac classifica como "filosófico”, o escritor pretende esboçar "um quadro dos sofrimentos morais do século”. O herói, Raphaël de Valentin, desencantado com uma vida que não lhe reserva senão miséria e desilusões, está prestes a suicidar-se. Eis então que descobre, entrando em um antiquário, um pedaço de pele de camurça, capaz de satisfazer a todos os seus desejos. Mas, à medida que o talismã vai atendendo aos pedidos de Raphaël, a pele do animal também vai diminuindo de tamanho, o que significa que sua vida vai se consumindo paralelamente e na mesma proporção. Instala-se então uma luta desesperada entre o desejo de prazeres oferecidos pelo talismã e a vontade de preservar a própria vida. Embora essa obra não possa ser considerada como “fantástica”, nos termos em que hoje se define o termo, já que a leitura que se pode fazer do romance permanece puramente alegórica, a presença do elemento “estranho” - a pele de camurça autoriza as diversas aproximações com a obra do autor alemão, que passa a servir de referência para toda produção onde irrompem a fantasia, o sobrenatural e o "estranho".

A esse respeito, o julgamento mais pertinente fica por conta de Gérard de Nerval, que, além de traduzir Hoffmann, também se interessa pelo lado "noturno" da natureza tão apreciado pelo contista alemão, ele que, como poeta peculiar, transita entre o real o irreal, misturando vida interior e mundo exterior, tal como figura na introdução aos leitores que Hoffmann faz ao conto "Aventures de la nuit de Saint-Sylvestre": "O viajante entusiasta, cujo álbum nos fornece esta fantasia à maneira de Callot, separa nitidamente tão pouco sua vida interior da vida exterior, que teríamos dificuldade em apontar de modo distinto os limites entre uma e outra ..."*

Philothée O’Neddy, um dos chamados “petits romantiques français”, escreve na Introdução à sua obra Feu et flamme, datada 
de 10 de agosto de 1833: "Como vocês, eu também desprezo, com toda a grandeza de minha alma, a ordem social e, sobretudo, a ordem política, excremento da primeira"* . Na verdade, todos os jovens integrantes do grupo se revoltam e, para sustentar seu desprezo do mundo, em vez de adotarem o caminho da evasão pelo sonho acordado ou noturno - o que faz Charles Nodier, por exemplo -, buscam um procedimento comparável ao da magia e se vêem a si próprios como profetas de seu tempo. Como conclui Castex, acabam falhando, pois não se sentindo livres, todo-poderosos, nem tampouco iguais a Deus em brilho e excelência, confessam-se "malditos" e "escravos", e explodem sua revolta, conforme atestam as palavras de Pétrus Borel, ao final de Champavert: "Em Paris há duas cavernas, uma de ladrões, outra de assassinos; a dos ladrões é a Bolsa; a dos assassinos é o Palácio de Justiça”". Assim, o "mito Hoffmann”, com sua carga de transgressão, também vem inspirar a atitude romântica exacerbada dos "petits romantiques" franceses.

O fato é que Hoffmann passa a ser um parâmetro para a apreciação de obras literárias com as quais apresenta um certo grau de parentesco, além de servir de referência para aquilo que críticos e escritores tentam cernir como particular a um gênero chamado "fantástico”. O crítico A. Legoyt chama a atenção para o Melmoth réconcilié, outra obra de Balzac, que ele define como "um conto no estilo de Hoffmann"*. Balzac, em carta a seu amigo Henry Beyle, nome verdadeiro de Stendhal, dá alguns conselhos ao escritor com respeito a Charteuse de Parme, tomando Hoffmann como parâmetro para a identificação de uma literatura de imaginação que, segundo ele, não deve estar ausente do romance: "Hoffmann, o escritor mais fantástico, nunca esqueceu de obedecer a essa lei, sem exceção, nas regras do romance!"*.

Entretanto, quando o fantástico começa efetivamente a triunfar na França, é imediatamente submerso por uma literatura que se torna "moda” e já ressurge de certo modo esvaziada de seu conteúdo crítico e inovador. Um exemplo bastante contundente desse desgaste pode ser observado em "Onuphrius Whply”, de Théophile Gautier. Uma primeira versão surge em agosto de 1832, na France Littéraire, mas o título, assim como parte do texto, serão modificados para sua reedição, no ano seguinte, na coletânea satírica Les Jeunes France (1833), onde o conto "Onuphrius Wphly" se transformará em "Onuphrius ou
" (apud Castex, Pierre. Georges. "Frénésie roman tique. Les Petits romanti ques français". Em: Cahiers du Sud, 1949: 34.)

* (apud Castex, Pierre Georges. "Frénésie romantique. Les Petits romantiques français". Op. cit.: 35.)

" (Legoyt apud Teichmann, Elizabeth. La fortune d'Hoff. mann en France. Op. cit. 150.)

* (Balzac apud Teichmann Elizabeth. La fortune d'Hoffmann en France. Op. cit.: 182.) 
os vexames fantásticos de um admirador de Hoffmann". Apesar da admiração que Gautier nutria pelo escritor alemão, tudo leva a crer que a nova versão publicada na revista do grupo de militantes da poesia, da arte e da revolta, à maneira do Sturm und Drangalemão, seja uma sátira dos excessos cometidos pelos "fantastiqueurs", de um modo geral, e que esta paródia se remeta diretamente à obra hoffmanneana.

Onuphrius é um jovem pintor que se alimenta de leituras de contos fantásticos que o mantêm em permanente exaltação imaginativa. Ora, o protagonista está tão absorvido pelas visões fantasmagóricas que as leituras mal digeridas lhe proporcionam, que se vê impedido de terminar o retrato de sua amada. O diabo e suas visões satânicas acabam por tomá-lo inteiramente, fazendo-o delirar na completa loucura, razão pela qual Onuphrius crê estar sendo enterrado vivo. Neste momento, ele assiste ao triunfo de seu rival, que se apropria do sucesso de seus quadros e de suas poesias. Após sua morte, os leitores estão autorizados a concluir que ela é provocada por um excesso de leitura de contos fantásticos de Hoffmann, como sugere o próprio título.

O Salmigondis, de fevereiro de 1833, publica um texto de George Sand intitulado "Cora", no qual ela descreve os danos que a leitura dos contos de Hoffmannn pode provocar na mente de um jovem apaixonado. Ao contrário de Onuphrius, o rapaz apaixona-se por Cora, filha de um comerciante provinciano, e vê na moça "o tipo mais completo da beleza fantástica". E, por causa de Hoffmann, formam-se dois grupos de pessoas na cidade, que discutem, uns a favor, outros contra os Contes fantastiques. Cora, próxima da personagem Clara, de Homem de areia, acaba casando-se com um ajudante de farmácia, abandonando o narrador que deixa de vez a cidade para tentar curar-se do desencanto amoroso. Neste texto, a intenção parodística é evidente, mas, ao mesmo tempo, a ironia aí presente pode também apontar para uma dupla direção: tanto pode ser a inversão parodística do célebre conto de Hoffmann, como a ironia crítica contra a sociedade burguesa, que não compreende o contista alemão e sua obra de pura imaginação. Através da ambigüidade, George Sand faz, pelo recurso da paródia, uma denúncia, tanto do "burguês filisteu" contra o "artista maldito" e dos defensores da literatura realista quanto do exagero praticado por autores da literatura romântica, que enveredam pelo fantástico para satisfazer uma questão de modismo literário passageiro. 
Assim, com a mesma velocidade com que Hoffmann foi transformado em ídolo e referência para a produção literária romântica da primeira metade do século XIX francês, o contista alemão acaba sendo o responsável por aquilo que alguns escritores denunciam como uma saturação da literatura romântica.

No período entre 1836 e 1840, o ano de 1836 marca um último esforço de divulgação empreendido pelo tradutor Egmont. Sua tradução se destaca pela elegância e precisão, assim como pelo prefácio no qual Hoffmann é reabilitado. Após 1840, a literatura fantástica perde sua relativa hegemonia para ganhar novo alento entre 1856 e 1865, época em que Baudelaire se faz o introdutor de Edgar Allan Poe junto ao público francês, fazendo pela literatura americana aquilo que Loève-Veimars havia feito pela literatura germânica. Caberia, contudo, ressaltar que, mesmo que a campanha em favor de Hoffmann tenha se tornado menos efetiva depois dos anos 1830, não se pode esquecer que o contista deixa definitivamente sua marca na série literária francesa.

Após a sua primeira fase, na qual os contos de Théophile Gautier vão buscar inspiração diretamente na obra de Hoffmann - acabando por se traduzir em paródias desencantadas do próprio mito romântico e do absoluto literário criado pela geração romântica -, nos contos da segunda fase de Gautier, percebe-se uma renovação do gênero. Sobretudo em "Le spirite", pode-se constatar que todo o sistema literário francês já estava significativamente modificado. A exploração detalhada da realidade lugares e pessoas, interiores e exteriores - já se apoiava em novos modelos, como os fornecidos pela narrativa de Flaubert, por exemplo. Da mesma forma, outros autores da literatura fantástica vindos da tradição anglo-saxônica, tais como Edgar Allan Poe, traduzido por Baudelaire, e o maravilhoso ancorado nos contos populares de Achim von Arnim, traduzidos para o francês e com um prólogo do próprio Gautier, em 1856, atestam o fôlego da literatura fantástica, que permanece como uma das manifestações ficcionais do século, tendo contribuído para o incremento do movimento romântico. Embora relativamente pouco conhecido nos dias de hoje, o conto "Le spirite" de Gautier inspira a criação de vários autores do final do século XIX, com a literatura que se define posteriormente como simbolista e decadente, termo, aliás, que já aparece no relato de Gautier, quando este faz referência à cidade de Veneza, no conto citado. 
" (de Nerval, Gérard. "Au. rélia". Em: Oeuvres com plètes, $2^{\mathrm{a}}$ parte, t. 1 , Paris: Gallimard, 1980: 385.6.)
Após os anos 1850, sob a nítida influência de Edgar Allan Poe, os relatos fantásticos dão prova de uma evolução do gosto, sobretudo pelas obras de Lautréamont, Villiers de l'Isle-Adam e Guy de Maupassant. Em uma época de esgotamento de valores, tanto de ordem social, quanto moral e religiosa, a literatura fantástica vem à cena mais uma vez para expressar a tensão entre a crença mágica em poderes misteriosos de ídolos, por um lado, e, por outro, a moderna transformação desses poderes em força espiritual e humanística, ou seja, a confiança nos poderes emocionais e cognitivos do próprio homem. Pois, como percebe Gérard de Nerval, "quando a alma flutua incerta entre a vida e o sonho, entre a desordem do espírito e o retorno à reflexão consciente, é no pensamento religioso que devemos buscar socorro", reconhece o narrador de Aurélia. Contudo, completa ele mais adiante, "para nós, nascidos em dias de revoluções e tempestades, quando todas as crenças se quebram", torna-se bem difícil "reconstruir o edifício místico, cuja figura bem traçada somente os inocentes e os simples admitem em seus corações"*.

Como vimos, na França, mais tarde do que na Alemanha ou do que na Inglaterra, o rótulo "romântico" serviu de símbolo de combate. A literatura fantástica, entendida como uma das manifestações literárias do romantismo, apresentou-se como uma das maneiras de conduzir esse combate, levando, particularmente no contexto francês, ao questionamento do estatuto do literário e à renovação estética. Embora tivessem trilhado caminhos diferentes e a expressão da retomada da liberdade da ficção tivesse se atualizado em obras diversas entre si, o ponto em comum fica por conta da consciência de um momento de crise da representação. As novas manifestações estéticas aparecem então como fruto de um sentimento de compensação e como uma tentativa de resgate de algo que se tenta recuperar através da ficção, buscando impedir os descaminhos que esta corre o risco de continuar trilhando.

Entendemos que é exatamente porque o fantástico participa de duas ordens - o sobrenatural e o natural - que ele se constitui elemento privilegiado para o estudo das relações entre as exigências do cânone realista - hegemônico na maioria das vezes - e a resistência da liberdade da ficção. O fantástico que ressurgiu na França a partir das traduções dos contos de Hoffmann possibilitou o deslocamento do conceito de verossi- 
milhança e instaurou o espaço da literatura assumida como ficção, em reação ao "gosto francês" e à estratégia discursiva realista. Esta, embora "contratualmente" entendida como obra de imaginação, busca esconder os procedimentos do "ato de fingir" com o intuito de aproximar o máximo possível essa literatura do tex to documental.

Em reação à estética realista e aos excessos da escola "frenética", delinearam-se neste período as manifestações de uma literatura que tenta refletir sobre si mesma, que relativiza os campos do natural e do sobrenatural, do tempo cronológico e do tempo subjetivo, do real e do irreal, devolvendo à literatura seu papel de obra de imaginação e redimensionando a questão do sujeito e suas representações. A originalidade da retomada do fantástico pelo movimento romântico reside na renovação das idéias estéticas do Ocidente e no aparecimento de uma nova sensibilidade filosófica, abrindo uma perspectiva para a literatura que se reconhece como moderna, explorando aquilo que se percebia como "indizível”, isto é, a experiência dos limites e a fala a partir de outros lugares, tais como o sonho e a loucura, tão bem trabalhados posteriormente pelos simbolistas. 
Palavras-chave

literatura fantástica romantismo

quebra de cânone crise da representação

Keywords fantastic literature Romanticism ruptures in the canon crisis of representation

\section{Maria Cristina Batalha}

Doutora em Literatura Comparada pela Universidade Federal Fluminense e Professora Adjunta da Universidade do Estado do Rio de Janeiro. É autora de diversos artigos publicados em revistas especializadas nacionais e internacionais.

\section{Resumo}

Se o gênero fantástico surge na França com as obras Le diable amoureux, de Jacques Cazotte (1772), e Le manuscrit trouvé à Saragosse, de Jean Potocki (1805), estas permanecem estreitamente vinculadas aos modelos narrativos do século XVIII e não conseguem impor-se na cena literária dominada pelo princípio orientador da verossimilhança. Na Alemanha, a explosão de fantasia, presente no maravilhoso de Achim von Arnim, traz um fermento novo ao romantismo nesse país e possibilita a evolução do gênero até alcançar a riqueza de recursos ficcionais trabalhados por E. T. A. Hoffmann em seus contos fantásticos. É então a partir das traduções da obra do contista alemão, ou seja, a partir de 1829, que o caminho da literatura fantástica é restabelecido neste país, inspirando alguns autores românticos franceses. No breve intervalo entre os anos 1830 e 1840, a literatura fantástica se apresenta, mais uma vez, como uma resposta à crise política e ao marasmo no qual a ficção francesa estava mergulhada, ganhando projeção e foro de literatura hegemônica. Mas, como mais um mito romântico, ela perde seu fôlego e acaba como paródia de si mesma na própria obra ficcional de Gautier, contista fantástico de primeira ordem, e que, pelo viés da ironia, promove a crítica à literatura de seu tempo.

\section{Abstract}

The fantastic as a genre starts in France with the works Le diable amoureux of Jacques Cazotte (1772) and Le manuscrit trouvé à Saragosse of Jean Potocki(1805), but they remain closely linked to the narrative patterns of the eighteenth century and do not succeed in asserting themselves in the literary scene dominated by the guiding principle of verisimilitude. In Germany, the outburst of fantasy found in the marvelous of Achim von Arnim brings a new stimulus to roman-

\section{Résumé}

Le genre fantastique surgit en France avec les oeuvres Le diable amoureux, de Jacques Cazotte (1772) et Le manuscrit trouvé à Saragosse, de Jean Potocki (1805). Celles-ci demeurent néanmoins étroitement liées aux modèles narratifs du XVIIIe siècle et n’arrivent pas à s'imposer sur la scène littéraire dominée alors par le principe de la vraisemblance. En Allemagne, l'explosion de la fantasie présente dans la littérature merveilleuse d'Achim von Arnim amène une levure nou- 
ticism in this country and enables the evolution of the genre up until it reaches the rich fictional resources worked by E. T. A. Hoffman in his fantastic tales. It is then from the translation of the work of the German short story writer, that is, from 1829 , that the way to the literature of the fantastic is established in that country, stimulating some romantic French writers. In the brief instance between the thirties and the forties, the literature of the fantastic presents itself, once more, as an answer to the political crisis and the sheer boredom in which the French literature found itself, achieving projection and the status of hegemonic literature. However, as another romantic myth, it runs out of vitality and ends up as a parody of itself in the fictional work of Gautier, a writer of outstanding short stories of the fantastic, which, by means of irony, promotes the criticism of the literature of his days. velle au romantisme dans ce pays et rend possible l'évolution du genre jusqu'à la richesse des ressources fictionnelles dont se sert E. T. A. Hoffmann dans ses contes fantastiques. C'est donc à partir des traductions de l'oeuvre du conteur allemand, à savoir 1829, que la voie de la littérature fantastique se rétablit en France et vient inspirer quelques auteurs romantiques de ce pays. Pendant la brève période entre les années 30 et 40, la littérature fantastique se présente une fois de plus comme une réponse à la crise politique et au marasme dans lequel la fiction française était engloutie, tout en acquérant le statut d'une littérature hégémonique. Cependant, comme autant de mythes romantiques, celle-ci perd son souffle et finit en parodie d'elle-même sous la plume de Gautier, conteur fantastique de premier ordre, et qui, par le biais de l'ironie, promeut la critique de la littérature de son temps.
Recebido em 13/10/2002 Aprovado em $12 / 07 / 2003$ 